\title{
Controlling Solvate Formation of a Schiff Base by Combining Mechanochemistry with Solution Synthesis ${ }^{\dagger}$
}

\author{
Vladimir Stilinović, Dominik Cinčić, Marija Zbačnik, and Branko Kaitner* \\ Department of Chemistry, Laboratory of General and Inorganic Chemistry, Faculty of Science, Horvatovac 102a, \\ University of Zagreb, 10000 Zagreb, Croatia
}

RECEIVED JUNE 21, 2012; REVISED OCTOBER 19, 2012; ACCEPTED OCTOBER 30, 2012

\begin{abstract}
A Schiff base dicarboxylic acid (1) was prepared by condensation of 2-hydroxy-1naphthaldehyde with 5-aminoisophthalic acid. Its solvates with pyridine (2a and $\mathbf{2 b}$ ) and dimethylformamide (3) were prepared by liquid-assisted grinding and by conventional solvent-based methods. All products were characterised by FT-IR spectroscopy, thermogravimetric analysis and differential scanning calorimetry. The structures of $\mathbf{1}, \mathbf{2 b}$ and $\mathbf{3}$ were determined by single crystal X-ray diffraction. $\mathbf{1}$ was found to be a pure Schiff base, $\mathbf{2 b}$ a pyridine solvate and $\mathbf{3}$ a dimethylformamide solvate monohydrate. In all three structures, the Schiff base molecule appears to be present as the ketoamine tautomer.(doi: $10.5562 / \mathrm{cca} 2111)$
\end{abstract}

Keywords: Schiff base, solvates, dicarboxylic acid, mechanochemistry, tautomerism

\section{INTRODUCTION}

Schiff bases are imines prepared by condensation of primary amines with carbonyl compounds. ${ }^{1}$ During the last five decades a vast number of structural studies on Schiff bases derived from hydroxyaryl aldehydes and their coordination compounds have been undertaken., ${ }^{2,3}$ Schiff bases have become some of the most typical ligands for coordinating transition and inner transition metal ions. ${ }^{4-7}$ This most commonly involves Schiff base ligands derived from salicylaldehyde and 2hydroxy-1-naphthaldehyde. ${ }^{8-12}$ Also, Schiff bases have been intensively used as synthetic intermediates ${ }^{13}$ and, more recently, as anion receptors. ${ }^{14-16}$ They have attracted particular interest due to their biological activity ${ }^{17,18}$ and as model systems for biological macromolecules. ${ }^{19,20}$ Solid-state thermochromism and photochromism are another characteristic of these compounds leading to their application in various areas of materials science. ${ }^{21-23}$ Schiff bases derived from $o$ hydroxyaromatic aldehydes and ketones have shown to be excellent models for the study of keto-enol tautomerism both in solution and in the solid state. ${ }^{24-28}$ Such Schiff bases have drawn attention due to their physical properties in the crystalline state which are greatly influenced by the topochemistry of the Schiff base molecules which in turn is highly affected by the crystal structure. ${ }^{29-33}$
During the past decade it became wellrecognised that solvent-free synthesis and mechanochemistry are effective for the efficient and rapid synthesis of a wide range of imines. ${ }^{34,35}$ In general, conventional synthesis by condensation of primary amines with carbonyl compounds in solution requires acid catalysis, removal of the generated water and removal of bulk solvent upon the isolation of the product. It is therefore of high interest that many of these reactions can be performed in a single step with quantitative yields by gas-solid, liquid-solid or solid-solid reactions. ${ }^{36-39}$ This approach circumvents the use of the bulk solvent, avoiding at the same time problems encountered in solution-based chemistry, such as low solubility of reactants and solvolysis or hydrolysis of products. Among these preparatory procedures, mechanochemical methods such as liquid-assisted grinding $(\mathrm{LAG})^{40,41}$ or ion- and liquid-assisted grinding

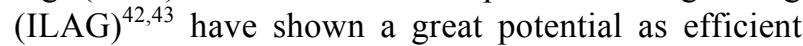
methods for supramolecular and covalent synthesis of new materials. ${ }^{44-47}$

Our group has recently reported mechanochemical synthesis of a Schiff base derived from 2-hydroxy-1naphthaldehyde and 2-aminobenzonitrile ${ }^{48}$ and described simultaneous covalent solvent-free synthesis and polymorphism control using neat grinding and seeding-assisted grinding (SEAG), i.e. neat grinding in the presence of seed crystals of the desired product.

\footnotetext{
$\dagger$ This article belongs to the Special Issue devoted to the $85^{\text {th }}$ anniversary of Croatica Chemica Acta.

* Author to whom correspondence should be addressed. (E-mail: kaitner@chem.pmf.hr)
} 


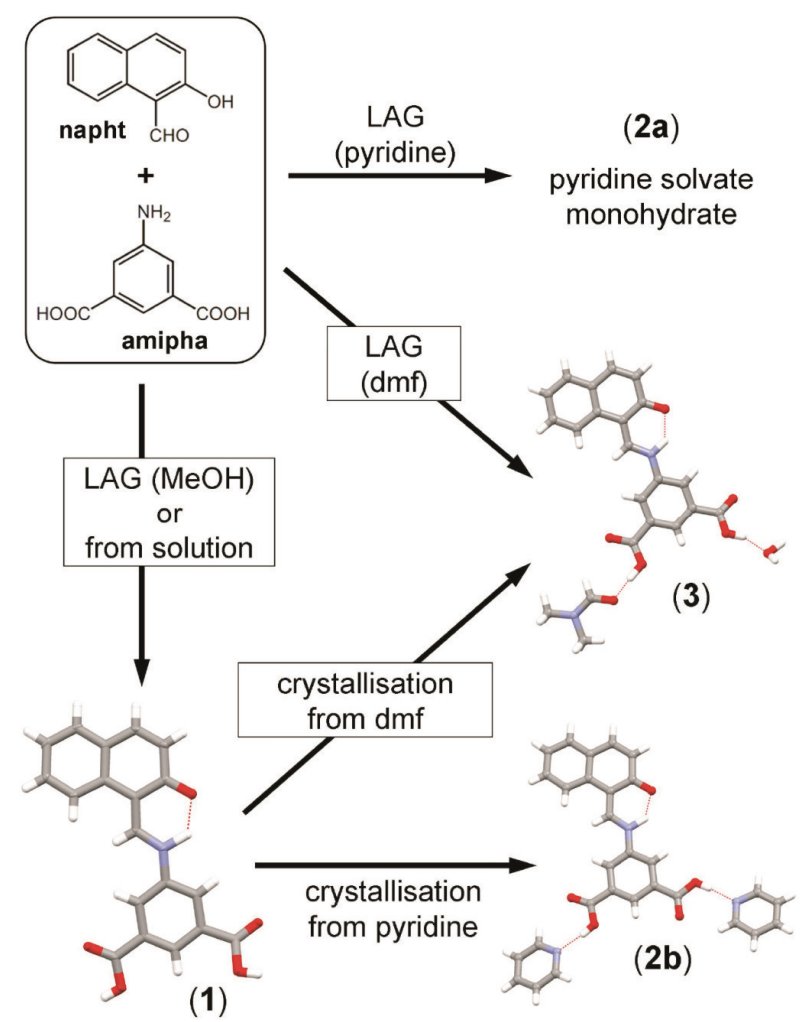

Figure 1. Summary of reactions to form Schiff base (1) and its solvates.

Herein we report the synthesis of 5-[(2-oxo- $2 \mathrm{H}$ naphthalen-1-ylidenemethyl)-amino]-bezene-1,3-dicarboxylic acid (1), Schiff base derived from 2-hydroxy-1naphthaldehyde (napht) and 5-amino-isophthalic acid (amipha) as well as its solvates with pyridine (2a and 2b) and dimethylformamide (3) (Figure 1). All products were characterised by FT-IR spectroscopy, thermogravimetric analysis (TGA), and differential scanning calorimetry (DSC). The structures of $\mathbf{1}, \mathbf{2} \mathbf{b}$ and $\mathbf{3}$ were determined by single crystal X-ray diffraction. To the best of our knowledge, this is the first structurally characterised Schiff base with two carboxylic groups bound to an aromatic ring of the $N$-substituent. ${ }^{2}$

\section{EXPERIMENTAL}

\section{Materials and Synthesis}

The starting materials, 2-hydroxy-1-naphthaldehyde and 5-aminoisophthalic acid were obtained from Acros Organics and Merck, respectively. Napht was recrystallised from methanol and amipha was used without further purification. Solvents were purchased from Kemika and T.T.T., Zagreb.

Compound 1 was synthesised by liquid-assisted grinding of a mixture of napht $(0.103 \mathrm{~g}, 0.600 \mathrm{mmol})$ and amipha $(0.109 \mathrm{~g}, 0.600 \mathrm{mmol})$ in the presence of 45 $\mu \mathrm{L}$ of methanol. The compound $\mathbf{2 a}$ was synthesised by liquid-assisted grinding of a mixture of napht $(0.103 \mathrm{~g}$, $0.600 \mathrm{mmol})$ and amipha $(0.109 \mathrm{~g}, 0.600 \mathrm{mmol})$ in the presence of $90 \mu \mathrm{L}$ of pyridine. The compound $\mathbf{3}$ was synthesised by liquid-assisted grinding of a mixture of napht $(0.103 \mathrm{~g}, 0.600 \mathrm{mmol})$ and amipha $(0.109 \mathrm{~g}$, $0.600 \mathrm{mmol})$ in the presence of $60 \mu \mathrm{L}$ of dimethylformamide. Grinding was performed in a stainless steel jar of $10 \mathrm{~mL}$ volume, using two stainless steel grinding balls, $7 \mathrm{~mm}$ in diameter. A Retsch MM200 grinder mill operating at $25 \mathrm{~Hz}$ frequency was used for the synthesis. Analysis of the products using PXRD revealed complete conversion of reactants into $\mathbf{1}, \mathbf{2 a}$ and 3 after $50 \mathrm{~min}, 40 \mathrm{~min}$ and $20 \mathrm{~min}$ grinding, respectively.

For solution-based synthesis of $\mathbf{1}$, napht $(1.72 \mathrm{~g}$, $0.010 \mathrm{~mol})$ and amipha $(1.81 \mathrm{~g}, 0.010 \mathrm{~mol})$, were dissolved in hot methanol $(30 \mathrm{~mL}$ and $20 \mathrm{~mL}$, respectively). The solutions were mixed and the resulting mixture left at room temperature. Yellow precipitate began appearing almost immediately. After $30 \mathrm{~min}$ it was separated from the mother liquor by filtration, and washed with methanol. Single crystals of 1 suitable for X-ray diffraction were obtained by the liquid phase diffusion procedure from dichloromethane solutions of the reactants (napht and amipha), which yielded orange crystals. $\mathbf{2 b}$ and $\mathbf{3}$ were prepared by crystallisation of $\mathbf{1}$ from pyridine and dimethylformamide, respectively. Single crystals of $\mathbf{2 b}$ suitable for X-ray diffraction were obtained by dissolution of $100 \mathrm{mg}$ of $\mathbf{1}$ in $3.0 \mathrm{~mL}$ of pyridine. The solution was allowed to evaporate slowly for 1 day at room temperature, yielding orange crystals. Single crystals of $\mathbf{3}$ suitable for X-ray diffraction were obtained by dissolution of $100 \mathrm{mg}$ of $\mathbf{1}$ in $2.0 \mathrm{~mL}$ of dimethylformamide. The solution was allowed to evaporate slowly for 5 days at room temperature, yielding orange crystals.

\section{Thermal and Spectroscopic Analysis}

Thermal analysis was carried out on Mettler Toledo TGA/SDTA 851 and DSC823 modules in sealed aluminium pans $(40 \mu \mathrm{L})$, heated in flowing nitrogen $(200$ $\mathrm{mL} \mathrm{min}^{-1}$ ) at $10{ }^{\circ} \mathrm{C} \mathrm{min}^{-1}$. The data collection and analysis was performed using the program package STARe Software 9.01. ${ }^{49}$ Infrared spectra were recorded on an EQUINOX 55 FTIR spectrophotometer using the $\mathrm{KBr}$ pellet method. The data collection and analysis was performed using the program package OPUS 4.0. ${ }^{50}$

\section{X-ray Diffraction Experiments}

Crystal and molecular structures of $\mathbf{1}, \mathbf{2 b}$ and $\mathbf{3}$ were determined by single crystal X-ray diffraction. Diffraction measurements were made on an Oxford Diffraction Xcalibur Kappa CCD X-ray diffractometer with graphite-monochromated $\operatorname{MoK\alpha }(\lambda=0.71073 \AA)$ radiation. ${ }^{51}$ 
Table 1. Crystal data and summary of experimental details for compounds $\mathbf{1}, \mathbf{2 b}$ and $\mathbf{3}$.

\begin{tabular}{|c|c|c|c|}
\hline & 1 & $2 \mathbf{b}$ & 3 \\
\hline Molecular formula & $\mathrm{C}_{19} \mathrm{H}_{13} \mathrm{NO}_{5}$ & $\mathrm{C}_{19} \mathrm{H}_{13} \mathrm{NO}_{5} \cdot 2 \mathrm{C}_{5} \mathrm{H}_{5} \mathrm{~N}$ & $\mathrm{C}_{19} \mathrm{H}_{13} \mathrm{NO}_{5} \cdot \mathrm{C}_{3} \mathrm{H}_{7} \mathrm{NO} \cdot \mathrm{H}_{2} \mathrm{O}$ \\
\hline$M_{\mathrm{r}}$ & 335.3 & 493.5 & 426.42 \\
\hline Crystal system & Triclinic & Monoclinic & Monoclinic \\
\hline Space group & $P \overline{1}$ & $P 2_{1}$ & $P 2_{1} / c$ \\
\hline \multicolumn{4}{|l|}{ Crystal data: } \\
\hline$a / \AA$ & $7.1802(6)$ & $6.1453(4)$ & $6.0236(2)$ \\
\hline$b / \AA$ & $8.3777(9)$ & $25.5518(19)$ & $22.0929(11)$ \\
\hline$c / \AA$ & $12.6430(12)$ & $7.6712(6)$ & $14.9471(7)$ \\
\hline$\alpha /^{\circ}$ & $100.073(8)$ & 90 & 90 \\
\hline$\beta / \circ$ & $106.148(7)$ & $93.348(7)$ & $91.365(4)$ \\
\hline$\gamma /{ }^{\circ}$ & $90.593(8)$ & 90 & 90 \\
\hline$V / \AA^{3}$ & $717.85(12)$ & $1202.50(15)$ & $1988.58(15)$ \\
\hline$Z$ & 2 & 2 & 4 \\
\hline$\rho_{\text {calc }} / \mathrm{g} \mathrm{cm}^{-3}$ & 1.551 & 1.363 & 1.424 \\
\hline$\lambda\left(\mathrm{Mo} K_{\alpha}\right) / \AA$, graphite monochromator & 0.71073 & 0.71073 & 0.71073 \\
\hline$T / \mathrm{K}$ & $150(2)$ & $295(2)$ & $150(2)$ \\
\hline Crystal dimensions $/ \mathrm{mm}^{3}$ & $0.31 \times 0.25 \times 0.02$ & $0.45 \times 0.32 \times 0.23$ & $0.31 \times 0.24 \times 0.15$ \\
\hline$\mu / \mathrm{mm}^{-1}$ & 0.114 & 0.095 & 0.107 \\
\hline$F(000)$ & 348 & 516 & 896 \\
\hline$h k l$ range & $-7,8 ;-9,9 ;-13.15$ & $-7,7 ;-32,32 ;-9,9$ & $-5,7 ;-27,23 ;-14,18$ \\
\hline Number of measured reflections & 3922 & 9063 & 10434 \\
\hline Number of independent reflections & 2482 & 5093 & 3886 \\
\hline Number of reflections with $I>2 \sigma(I)$ & 1305 & 3182 & 2137 \\
\hline Number of parameters & 238 & 345 & 324 \\
\hline$\Delta \rho_{\max }, \Delta \rho_{\min } / \mathrm{e} \AA^{-3}$ & $0.244,-0.265$ & $0.262,-0.246$ & $0.281,-0.257$ \\
\hline$R\left[F^{2}>4 \sigma\left(F^{2}\right)\right]$ & 0.0443 & 0.0805 & 0.0399 \\
\hline$w R\left(F^{2}\right)$ & 0.1366 & 0.204 & 0.0980 \\
\hline Goodness-of-fit, $S$ & 0.823 & 1.089 & 0.831 \\
\hline
\end{tabular}

The data sets were collected using the $\omega$ scan mode over the $2 \theta$ range up to $54^{\circ}$. The structures were solved by direct methods and refined using the SHELXS and SHELXL programs, respectively. ${ }^{52}$ The structural refinement was performed on $F^{2}$ using all data. The hydrogen atoms not involved in hydrogen bonding were placed in calculated positions and treated as riding on their parent atoms $\left[\mathrm{C}-\mathrm{H}=0.93 \AA\right.$ and $U_{\text {iso }}(\mathrm{H})=1.2$ $U_{\text {eq }}(\mathrm{C}) ; \mathrm{C}-\mathrm{H}=0.97 \AA$ and $\left.U_{\text {iso }}(\mathrm{H})=1.2 U_{\text {eq }}(\mathrm{C})\right]$ while the others were located from the electron difference map. All calculations were performed using the WinGX crystallographic suite of programs. ${ }^{53}$ The crystal data are listed in Table 1. Further details are available from the Cambridge Crystallographic Centre. ${ }^{54}$ Molecular structures of the compounds are presented by ORTEP- $3^{55}$ and their packing diagrams were prepared by Mercury. ${ }^{56}$

The powder X-ray diffraction (PXRD) experiments on the samples were performed on a PHILIPS PW 1840 X-ray diffractometer with $\mathrm{Cu} K_{\alpha 1}(1.54056 \AA)$ radiation at $40 \mathrm{~mA}$ and $40 \mathrm{kV}$. The scattered intensities were measured with a scintillation counter. The angular range $(2 \theta)$ was from 3 to $50^{\circ}$ with steps of $0.02^{\circ}$, and the measuring time was $0.5 \mathrm{~s}$ per step. The data collection and analysis were performed using the program package Philips $X^{\prime}$ Pert. ${ }^{57-59}$

\section{RESULTS AND DISCUSSION}

We first attempted the solvent-free synthesis of $\mathbf{1}$ by neat grinding of napht and amipha in the stoichiometric ratio 1:1. Ball milling for $30 \mathrm{~min}$ resulted in a mixture containing solid reactants, as evidenced by PXRD. Even after $80 \mathrm{~min}$ of neat grinding, no traces of product were detectable. Guided by the observation that small amount of a liquid phase can significantly enhance the scope and rate of mechanochemical synthesis we turned to LAG. ${ }^{12,23,46}$ To observe LAG mechanosynthesis, as well as to facilitate the characterisation of new materials by single crystal X-ray diffraction, LAG 


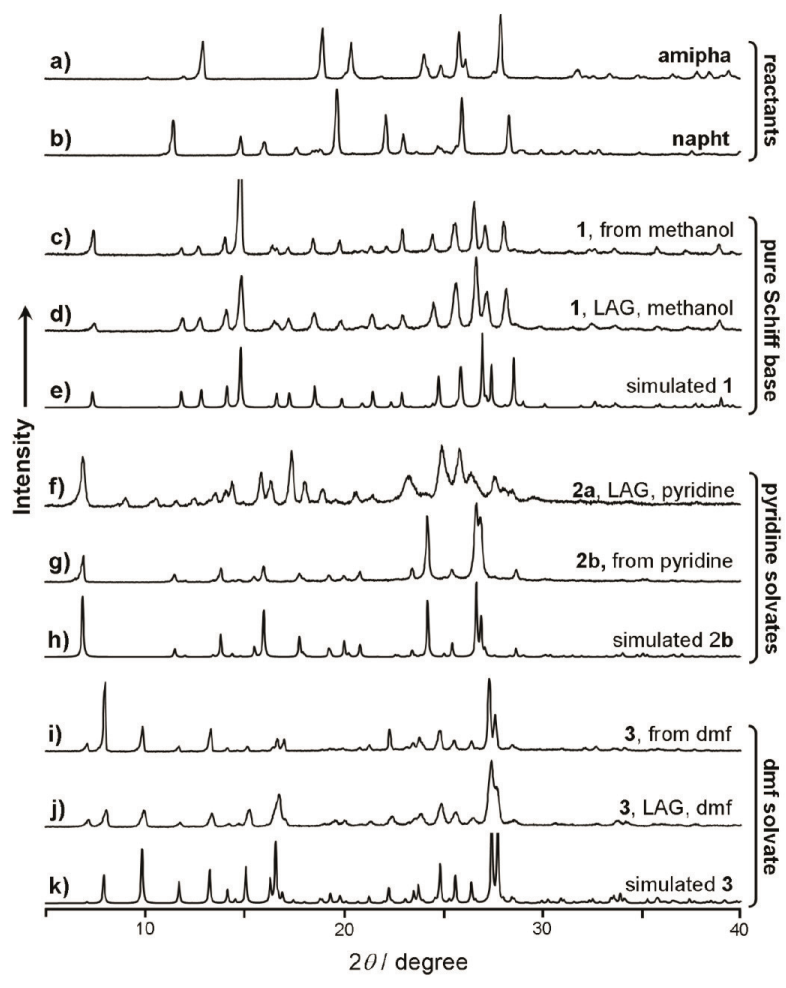

Figure 2. PXRD patterns of: a) 5-aminoisophthalic acid, b) 2hydroxy-1-naphthaldehyde, c) 1 prepared from a methanol solution, d) 1 prepared by liquid-assisted grinding, e) simulated pattern for 1, f) 2a prepared by liquid-assisted grinding, g) 2b prepared from a pyridine solution, $h$ ) simulated pattern for $\mathbf{2 b}$, i) $\mathbf{3}$ prepared from a dimethylformamide ( $\mathbf{d m f}$ ) solution, $\mathrm{j}$ ) 3 prepared by liquid-assisted grinding and $\mathrm{k}$ ) simulated pattern for 3 .

experiments were accompanied by conventional solution-based experiments. Addition of a small quantity of methanol to the reaction mixture, followed by grinding for $50 \mathrm{~min}$, quantitatively provided $\mathbf{1}$ which was identified by comparing its PXRD pattern with the one calculated from single crystal data (Figure 2c-e). Liquidassisted grinding of solid reactants in stoichiometric ratio and in the presence of a small amount of pyridine afforded a yellow powder, 2a, of PXRD pattern not identical to that of crystals prepared by crystallisation of $\mathbf{1}$ from pyridine, $\mathbf{2 b}$ (Figure 2f). TG curve of $\mathbf{2 a}$ shows a mass loss of $25 \%$ in the range between 45 and $230{ }^{\circ} \mathrm{C}$ which corresponds to a loss of one pyridine and one water per a Schiff base molecule (expected $22 \%$ ). This indicates that 2a is a pyridine solvate monohydrate of $\mathbf{1}$. Unfortunately the TG curve of $\mathbf{2} \mathbf{b}$ did not enable the determination of its composition since the curve shows a weight loss in the range between 70 and $140{ }^{\circ} \mathrm{C}$ of $24 \%$ (expected $19 \%$ for one pyridine molecule and $32 \%$ for two). Its correct composition was therefore determined by single-crystal X-ray structural analysis and found to be a pyridine solvate with two molecules of pyridine per a Schiff base molecule.
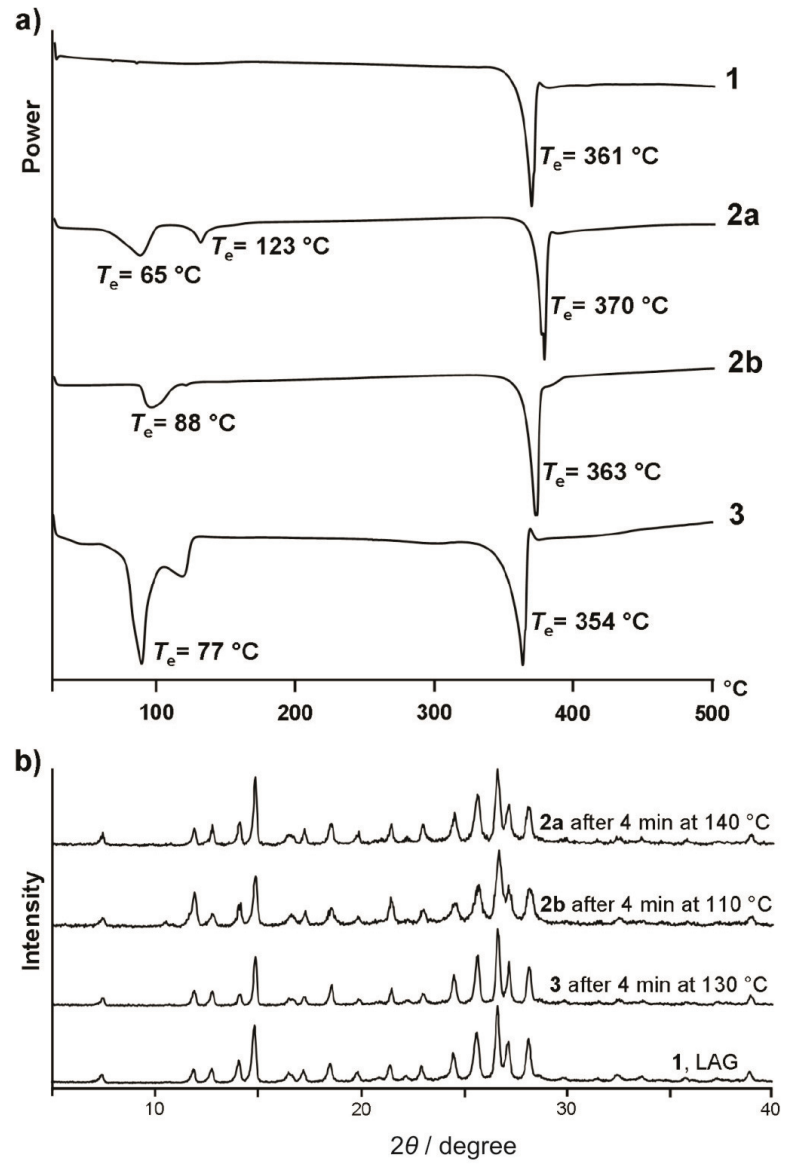

Figure 3. a) DSC curves of 1-3 and b) PXRD patterns of 2a, $\mathbf{2 b}$ and $\mathbf{3}$ after annealing.

Liquid-assisted grinding of napht and amipha in stoichiometric ratio and in the presence of a small amount of dimethylformamide afforded a yellow powder, $\mathbf{3}$, identical to that prepared by crystallisation of $\mathbf{1}$ from dimethylformamide as shown by the comparison of their PXRD patterns (Figure 2i and j). TG curves of $\mathbf{3}$ obtained by LAG and from solution are almost identical. In the range between 30 and $140{ }^{\circ} \mathrm{C}$ they show a mass loss of $23 \%$ (LAG) and $21 \%$ (from solution) which corresponds to a loss of one dimethylformamide and one water per a Schiff base molecule (expected $23 \%$ ). The differences in mass loss can be attributed to the differences of particle size in the two samples since the product obtained by LAG is more finely grained than the product obtained from solution. DSC curve of 1 shows one endothermic peak at $361{ }^{\circ} \mathrm{C}$, which corresponds to the melting point and decomposition (Figure 3a). Identical peaks are also observed in DSC curves of all the solvates as they were transformed into 1 by desolvation at lower temperatures. The TG curve of $\mathbf{1}$ presents no obvious weight loss from 25 to $340{ }^{\circ} \mathrm{C}$. In the range between 350 and $550{ }^{\circ} \mathrm{C}$, a mass loss of $62 \%$ can be attributed to evaporation and pyrolytic decompo- 
sition. 2a and 2b have remarkably different thermal properties as shown by corresponding DSC curves (Figure 3a). The DSC curve of $\mathbf{2 a}$ shows two endothermic peaks in the range between 50 and $160{ }^{\circ} \mathrm{C}(39.8 \mathrm{~kJ}$ $\mathrm{mol}^{-1}$ and $14.5 \mathrm{~kJ} \mathrm{~mol}^{-1}$ ) which correspond to the desolvation. The DSC curve of $\mathbf{2} \mathbf{b}$ shows only one endothermic peak $\left(28.9 \mathrm{~kJ} \mathrm{~mol}^{-1}\right)$ in the range between 70 and $120{ }^{\circ} \mathrm{C}$. The DSC curve of $\mathbf{3}$ shows two strong partly overlapping endothermic peaks $\left(90.3 \mathrm{~kJ} \mathrm{~mol}^{-1}\right)$ in the range between 50 and $130{ }^{\circ} \mathrm{C}$ which correspond to desolvation (Figure 3a). All three solvates transform into 1 upon desolvation as shown by PXRD patterns of desolvated products (Figure $3 b$ ).

IR spectra of all four compounds show strong bands corresponding to the $\mathrm{C}-\mathrm{N}$ stretching vibration at about $1620 \mathrm{~cm}^{-1}\left(1618 \mathrm{~cm}^{-1}\right.$ for $\mathbf{1}, 1625 \mathrm{~cm}^{-1}$ for $\mathbf{2 a}$, $1618 \mathrm{~cm}^{-1}$ for $2 \mathrm{~b}$ and $1621 \mathrm{~cm}^{-1}$ for 3 ). The spectra of all compounds also show strong bands corresponding to carboxyilic C-O stretching at $1705 \mathrm{~cm}^{-1}$ and $1693 \mathrm{~cm}^{-1}$ for 1 , at $1715 \mathrm{~cm}^{-1}$ for $2 \mathrm{a}, 1706 \mathrm{~cm}^{-1}$ and $1693 \mathrm{~cm}^{-1}$ for 2b and $1698 \mathrm{~cm}^{-1}$ for $\mathbf{3}$. The IR spectrum of $\mathbf{3}$ also exhibits a band at $1645 \mathrm{~cm}^{-1}$ corresponding to $\mathrm{C}-\mathrm{O}$ stretching of the dimethylformamide carbonyl group. All four samples show wide signals in the range between $2800 \mathrm{~cm}^{-1}$ to $3500 \mathrm{~cm}^{-1}$ corresponding to $\mathrm{N}-\mathrm{H}$ and $\mathrm{O}-\mathrm{H}$ stretching vibrations. These wide signals are the result of the superposition of several $\mathrm{N}-\mathrm{H}$ and $\mathrm{O}-\mathrm{H}$ stretching bands (corresponding to several $\mathrm{N}-\mathrm{H}$ and $\mathrm{O}-\mathrm{H}$ bonds in each compound) which are expectedly very wide due to the involvement of $\mathrm{N}-\mathrm{H}$ and $\mathrm{O}-\mathrm{H}$ groups in strong intramolecular and intermolecular hydrogen bonding.

The crystal structures of $\mathbf{1}, \mathbf{2 b}$ and $\mathbf{3}$ were determined by X-ray diffraction on single crystal samples (Figure 4) and their identity confirmed by comparing the calculated powder diffraction patterns with those obtained by measurement of the bulk material (Figure 2). The composition of $\mathbf{1}$ and $\mathbf{3}$ was found to be in accordance with the one deduced from the thermogravimetric measurements and $\mathbf{2 b}$ was found to be a pyridine solvate with two pyridine per a Schiff base molecule. The Schiff base molecule is in all three structures approximately planar with the dihedral angle between the mean planes of the naphthyl and isophtalyl groups of $8.7^{\circ}$ in $\mathbf{1}, 0.7^{\circ}$ in $\mathbf{2 b}$ and $3.1^{\circ}$ in $\mathbf{3}$. This planar conformation is in part stabilised by an intramolecular hydrogen bond between the atoms $\mathrm{O} 1$ and N1 $(2.574 \AA$ in 1, $2.545 \AA$ in $\mathbf{2 b}$ and $2.543 \AA$ in $\mathbf{3}$ ). As in $o$ hydroxynaphthalideneamine Schiff bases the hydrogen atom may travel along this hydrogen bond, and thus be bonded either to the oxygen or to the nitrogen atom, such molecules can exist in two tautomeric forms.

Here presented Schiff base appears to be present as the keto-amine tautomer in all three structures. This is evidenced by the position of the electron density maximum corresponding to the hydrogen atom partici-
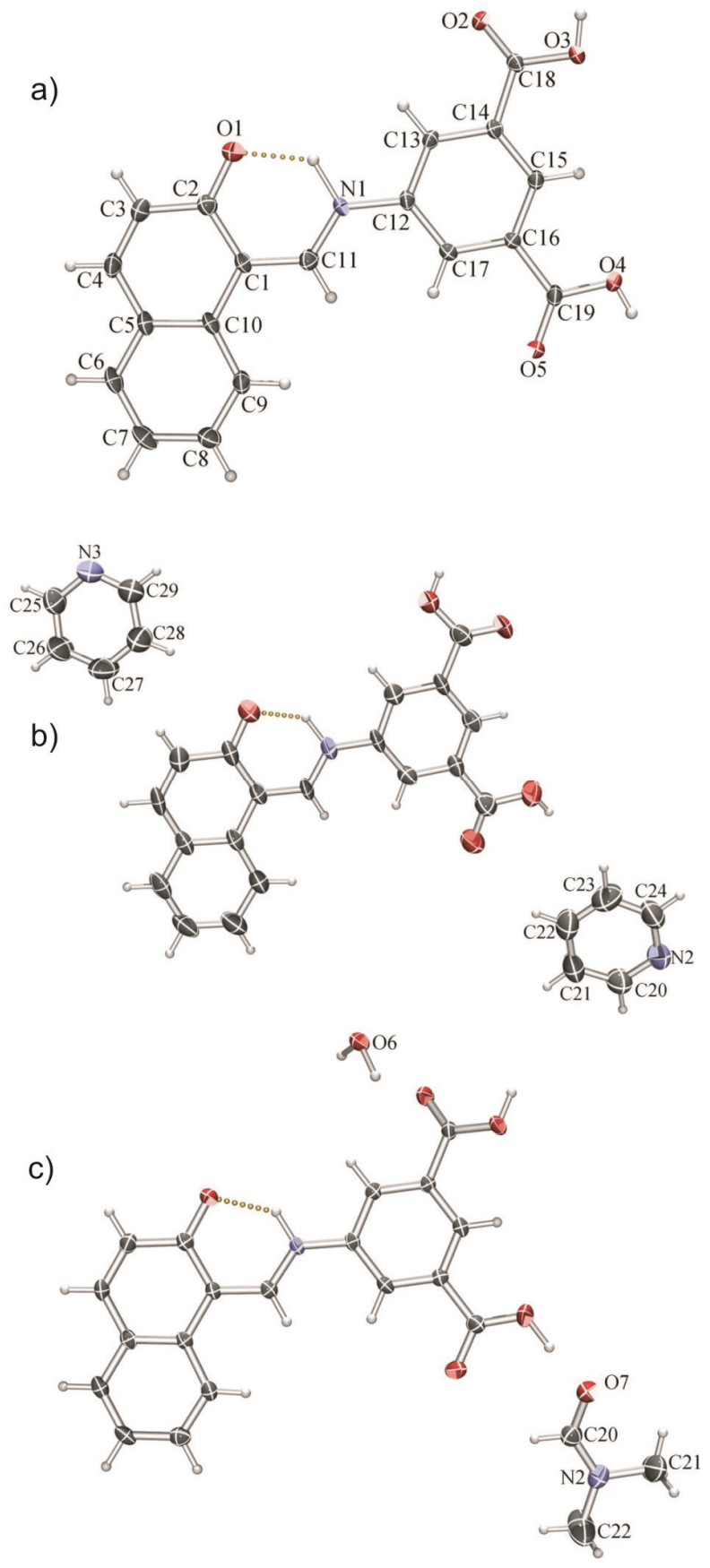

Figure 4. Ortep plots of the asymmetric units in a) 1, b) $2 \mathbf{b}$ and c) 3. The atom labelling scheme is the same for the Schiff base molecule and is shown in a). Thermal ellipsoids are plotted at $50 \%$ probability level, and the hydrogen atoms are shown as small spheres of arbitrary radius.

pating in the intramolecular hydrogen bond, which is in the vicinity of the nitrogen atom (Figure 5). However, while in $\mathbf{1}$ and $\mathbf{3}$ this position is rather unequivocal (Figure $5 \mathrm{a}$ and $\mathrm{b}$ ) with the maximal electron density of $\mathrm{ca}$ $0.8 \mathrm{e} / \AA^{3}$, in the case of $\mathbf{2} \mathbf{b}$ the positioning of the hydrogen atom from the electron difference map is somewhat dubious, since the maximal electron density (expectedly 
a)

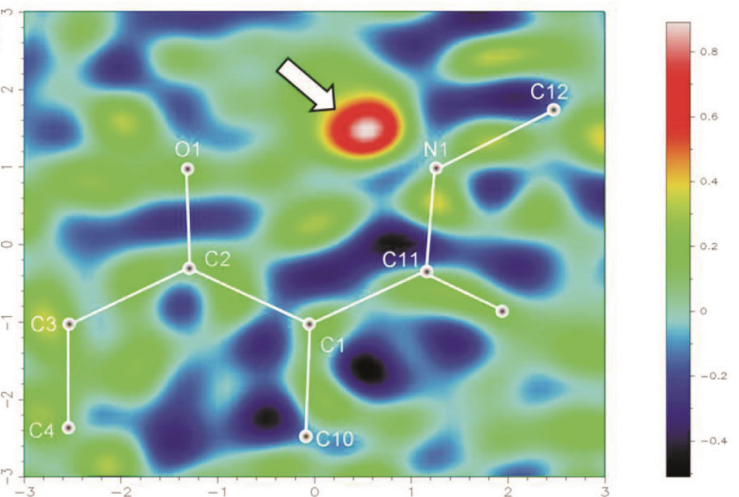

b)

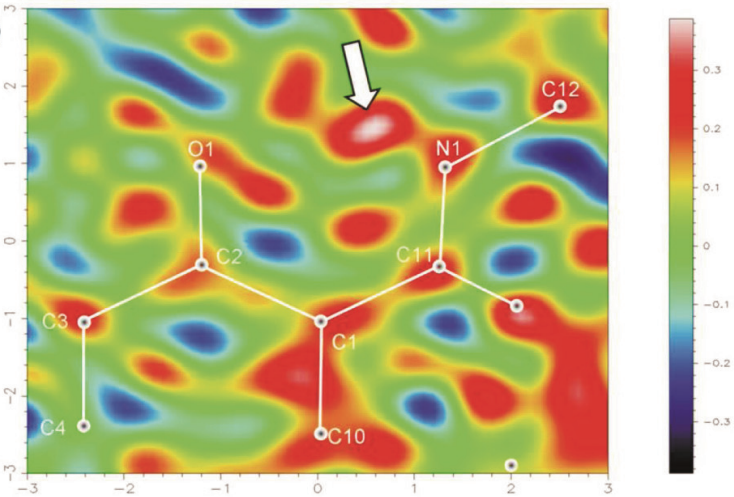

c)

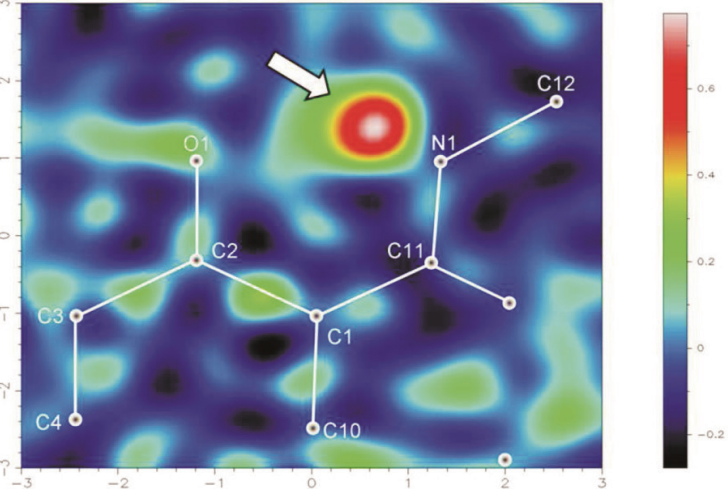

Figure 5. Electron difference maps of the section of Schiff base molecule participating in the intramolecular hydrogen bonding in a) $\mathbf{1}$, b) $\mathbf{2 b}$ and c) $\mathbf{3}$. The maximum corresponding to the location of the hydrogen atom is indicated by an arrow.

marking the position of the hydrogen atom) is only $c a$ $0.4 \mathrm{e} / \AA^{3}$, which is scarcely more than the artificial maxima which comprise the inherent unevenness of the electron difference map (Figure 5c). It was therefore necessary to study carefully whether the bond lengths and angles are in agreement whit those expected for keto-amine tautomer. ${ }^{3}$ For $\mathbf{1}$ and $\mathbf{3}$ these parameters do confirm the tautomeric form, with the $\mathrm{C} 2=\mathrm{O} 1$ bond length of $1.267 \AA$ in $\mathbf{1}(1.279 \AA$ in $\mathbf{3}), \mathrm{C} 1-\mathrm{C} 11$ of 1.400 $\AA$ in $\mathbf{1}(1.395 \AA$ in 3$)$ and $\mathrm{C} 11-\mathrm{N} 1$ of $1.321 \AA$ in $\mathbf{1}$ $(1.323 \AA$ in 3$)$. Both structures also show the shortening of $\mathrm{C} 3-\mathrm{C} 4$ bond (1.334 $\AA$ in $\mathbf{1}$ and $1.334 \AA$ in $\mathbf{3}$ ) as well as lengthening of other bonds within the same aromatic ring, consistent with the quinoid effect which is characteristic for keto-amine tautomeric forms of $o$ hydroxynaphthalideneamines. $\mathbf{2 b}$ also shows the same structural characteristics of the keto-amine tautomer, although with the $\mathrm{C}=\mathrm{O}$ and $\mathrm{C} 1-\mathrm{C} 11$ bonds somewhat longer $(1.281 \AA$ and $1.401 \AA), \mathrm{C} 11-\mathrm{N} 1$ somewhat shorter $(1.317 \AA)$, and the quinoid effect slightly less pronounced (C3-C4 bond of $1.343 \AA$ ). This could indicate that although the Schiff base molecules in $\mathbf{2 b}$ exist predominately as the keto-amine tautomer, a minute amount of enol-imino tautomer might be present. This would also account for the lower residual electron density in the position of the keto-amine hydrogen.

The complete absence of the enol-imino tautomer in $\mathbf{1}$ and $\mathbf{3}$ could be attributed to the specific intermolecular interactions that the Schiff base molecule is involved in their crystal structures. Namely, in both these structures atom $\mathrm{O} 1$ participates in hydrogen bonding as a hydrogen acceptor - for a carboxylic group of a neighbouring molecule in $\mathbf{1}(\mathrm{O} 3-\mathrm{H} 10 \cdots \mathrm{O} 1$ of $2.686 \AA)$ and a water molecule in $3(\mathrm{O} 6-\mathrm{H} 1 \mathrm{w} \cdots \mathrm{O} 1$ of $2.658 \AA)$. As a carbonyl oxygen atom is much stronger hydrogen acceptor than a hydroxyl one, the participation of $\mathrm{O} 1$ in such hydrogen bonding would expectedly reduce the probability of proton transfer from N1 to O1, thus stabilising the keto-amine tautomer. In $\mathbf{2} \mathbf{b}$ pyridine molecules are hydrogen bonded to both carboxyl groups, thus leaving no strong hydrogen donors free to bind to O1. This absence of hydrogen bond renders it more likely that in some molecules hydrogen atom is transferred from $\mathrm{N} 1$ to $\mathrm{O} 1$, and doing so, transforming the keto-amine into enol-imino tautomer.

Differences in the intermolecular hydrogen bonding in the structures of $\mathbf{1}, \mathbf{2 b}$ and $\mathbf{3}$ lead to significant differences in their crystal packing (Figure 6). In 1 each molecule acts as a donor and an acceptor of $\mathrm{O} 3-\mathrm{H} 10 \cdots \mathrm{O} 1$ hydrogen bonds with the same neighbour which leads to the formation of centrosymmetric dimers through a $R_{2}^{2}(22)$ hydrogen bonding motif (Figure 7). This leaves the other carboxyl group free to bond with a carboxyl group of another neighbouring molecule via the centrosymmetric $R_{2}^{2}(8)$ homosynthon characteristic for carboxylic acids. This combination of hydrogen bonds leads to the formation of chains of molecules along the [01-1] crystallographic direction. The chains are further connected via weak $\mathrm{C}-\mathrm{H} \cdots \mathrm{O}$ hydrogen bonds into approximately planar sheets which are stacked along the $a$ axis. This hydrogen bonding network can be identified as the cause of relatively high melting point of $\mathbf{1}$ in comparison to other Schiff bases of similar molecular mass.

In $\mathbf{2 b}$ both carboxyl groups of a Schiff base molecule are hydrogen bonded to pyridine molecules. The location of the hydrogen atom as well as the geometric 
a)

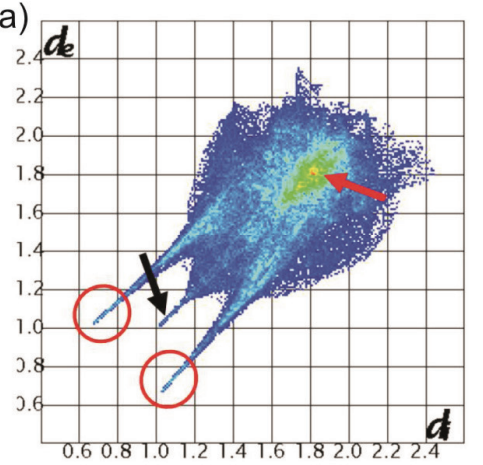

b)

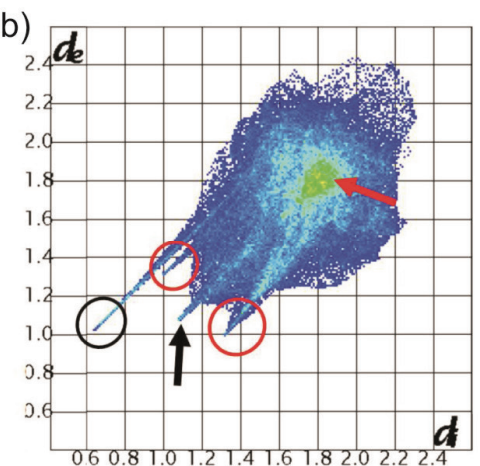

c)

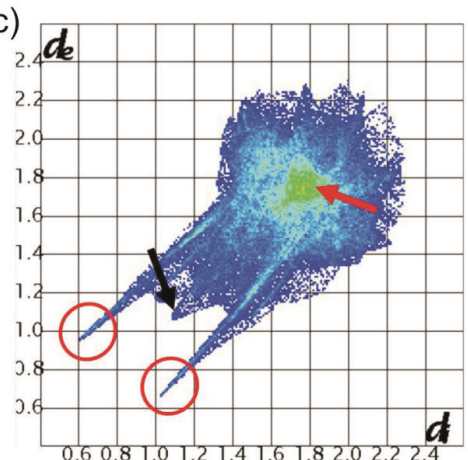

Figure 6. Two-dimensional fingerprint plot for: a) compound $\mathbf{1}$, b) a pyridine solvate $\mathbf{2 b}$, c) a dimethylformamide solvate 3 (marked corresponding regions: red circle for $\mathrm{O} \cdots \mathrm{H}$ contacts, black circle for $\mathrm{N} \cdots \mathrm{H}$ contacts, red arrow for $\mathrm{C} \cdots \mathrm{C}$ contacts and black arrow for short $\mathrm{H} \cdots \mathrm{H}$ contacts).

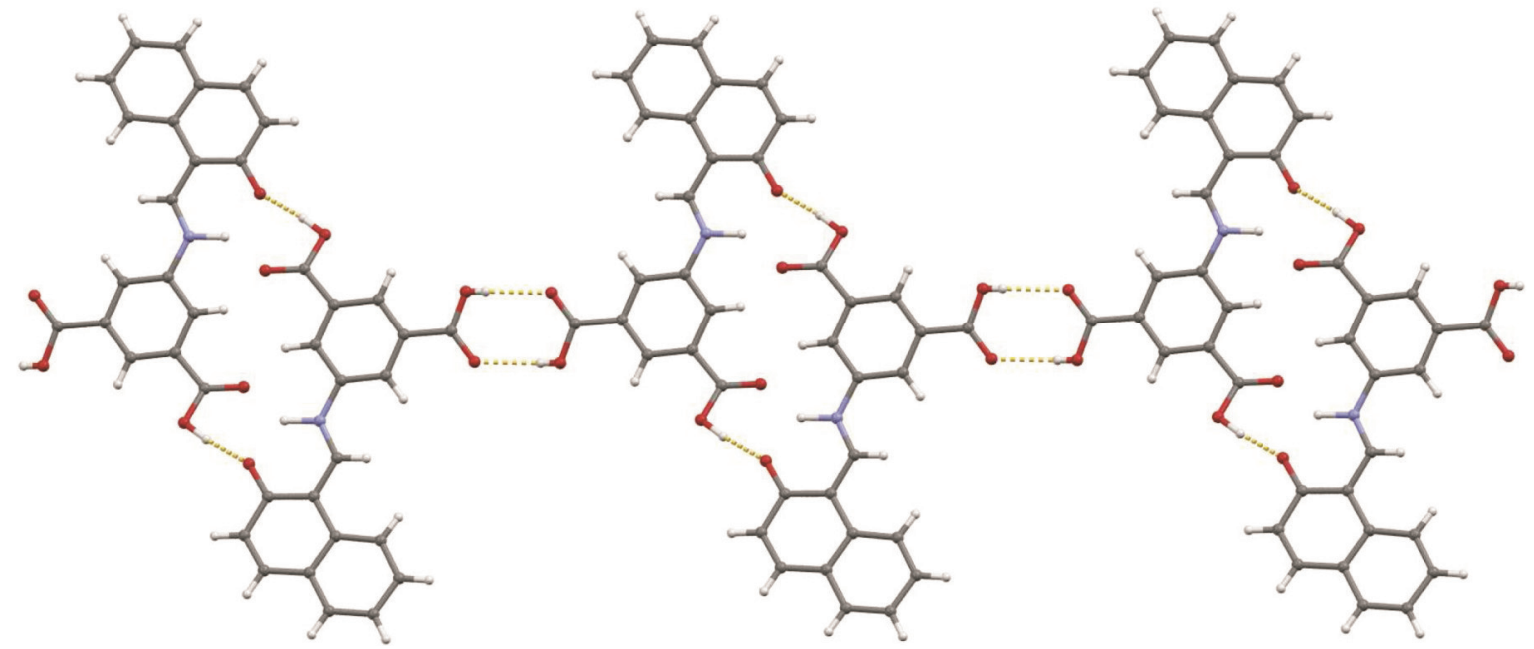

Figure 7. Chains of hydrogen bonded molecules in the crystal structure of $\mathbf{1}$.

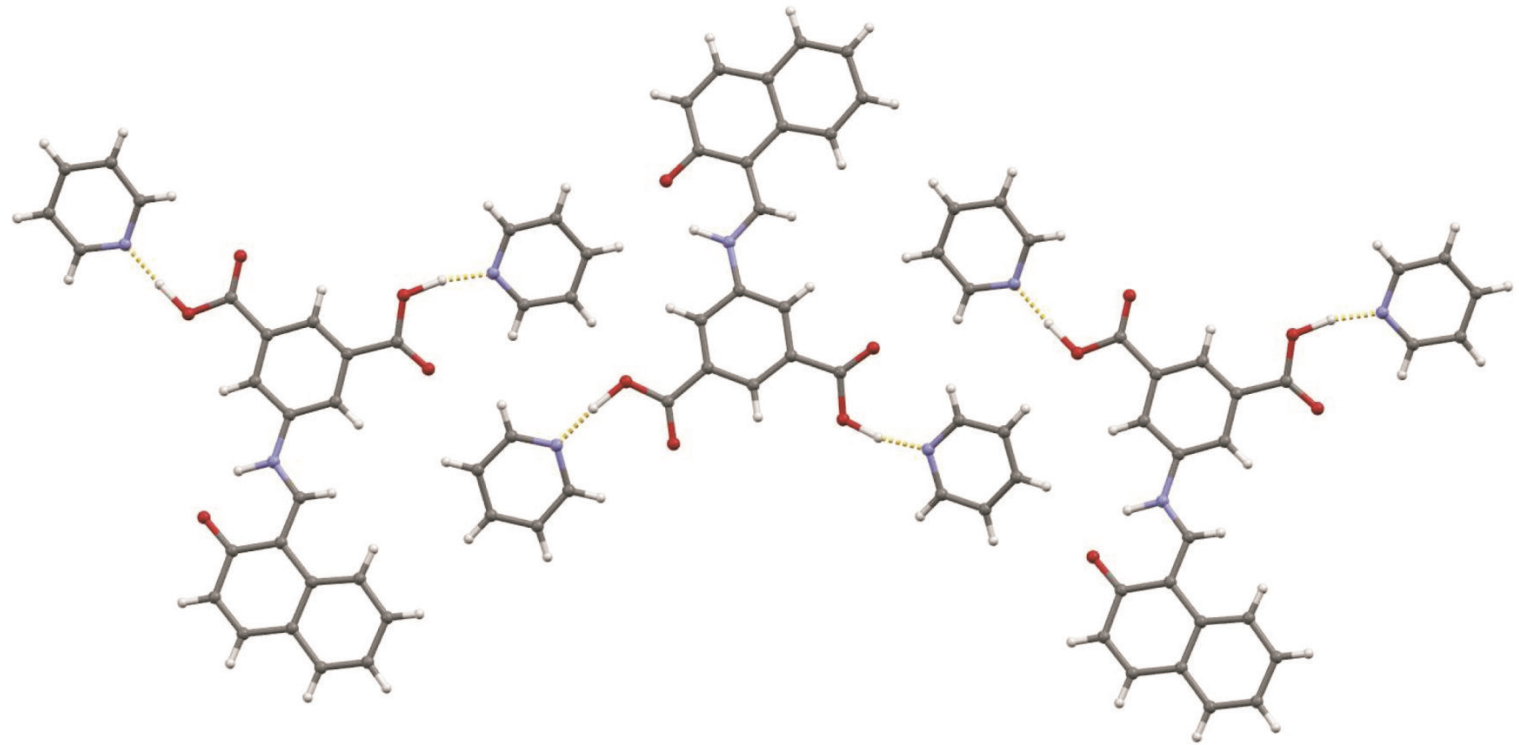

Figure 8. Packing of molecular adducts in the crystal structure of $\mathbf{2 b}$. 


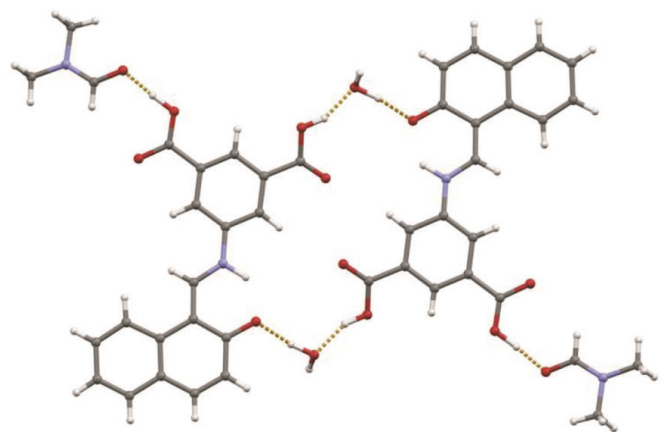

a)

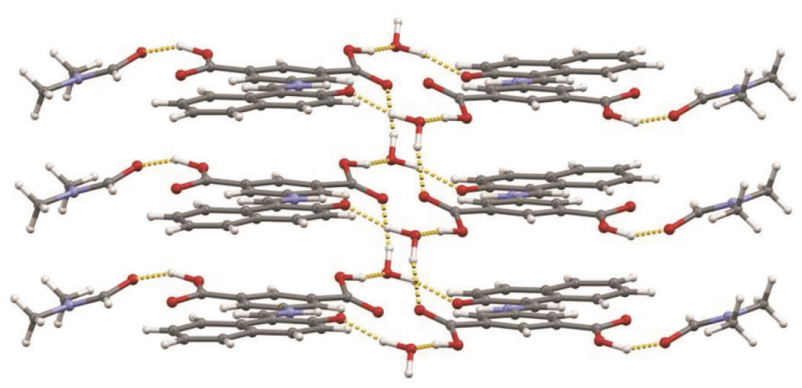

b)

Figure 9. a) Centrosymmetric hexamers in the crystal structure of $\mathbf{3}$ and b) their bonding into chains.

parameters of carboxyl groups (carbonyl bond lengths C18-O3 of $1.206 \AA$, C19-O5 of $1.189 \AA$, hydroxyl C18-O2 of $1.321 \AA, \mathrm{C} 19-\mathrm{O} 4$ of $1.340 \AA$ ) and pyridine rings $\left(\mathrm{C} 20-\mathrm{N} 2-\mathrm{C} 24\right.$ of $116.5^{\circ}$ and $\mathrm{C} 26-\mathrm{N} 3-\mathrm{C} 30$ of $116.7^{\circ}$ ), are in accordance with the position of the hydrogen atom on the carboxyl oxygen, thus proving that $\mathbf{2 b}$ is indeed a pyridine solvate, rather than a pyridinium salt. The pyridine rings are approximately coplanar with the isophtalyl group (dihedral angles of $21.3^{\circ}$ and $11.2^{\circ}$ ), due to additional $\mathrm{C}-\mathrm{H} \cdots \mathrm{O}$ hydrogen bonds between the pyridine molecules $(\mathrm{C} 20-\mathrm{H} 20 \cdots \mathrm{O} 3$ of 3.293 $\AA$ and $\mathrm{C} 30-\mathrm{H} 30 \cdots \mathrm{O} 5$ of $3.280 \AA$ ). The connection between the formation of planarity of supramolecular aggregates of pyridines and acids has already been well documented both with carboxylic acids ${ }^{60,61}$ and substituited phenols. ${ }^{62}$ These three-molecular aggregates are further connected by weak interactions into layers which are stacked along the [101] direction (Figure 8).

In 3 the water molecule which is a hydrogen donor to the $\mathrm{O} 1$ atom of a Schiff base molecule, also acts as an

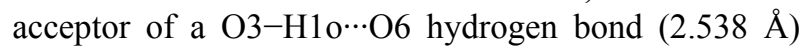
with a carboxyl group from a neighbouring Schiff base molecule. The same neighbour is also an acceptor of a O6-H1w‥ 1 hydrogen bond with a second water molecule which in turn acts as an acceptor of a carboxyl hydrogen from the first Schiff base molecule. This leads to a hydrogen bonded centrosymmetric ring of $R_{4}^{4}(26)$ topology, which corresponds to the $R_{2}^{2}(22)$ ring in the structure of 1 , with a water molecule interpolated between the carboxylic group and $\mathrm{O} 1$ carbonyl oxygen. Unlike in 1, however, the remaining carboxyl groups do not bind to carboxyl groups of neighbouring molecules, but rather to solvent $\mathbf{d m f}$ molecules, forming thus a centrosymmetric hexamer (Figure 9). The dmf molecules are disordered so that the formyl groups in two components are twisted by $180^{\circ}$. In the major component $(56 \%)$ the formyl carboxyl oxygen of the $\mathbf{d m f}$ molecule is hydrogen bonded to $\mathrm{O} 4$ carboxyl atom

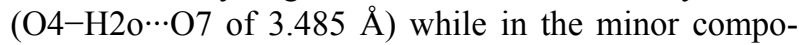
nent is hydrogen bonded to O5 carboxyl atom
$(\mathrm{O} 5-\mathrm{H} 20 \mathrm{a} \cdots \mathrm{O} 7 \mathrm{a}$ of $3.566 \AA)$. This rotation of the formyl group does not influence the position of the dimethylamino group, so both components occupy the same position in the crystal structure. Hydrogen bonding of the formyl carboxyl oxygen however requires the O4-C19-O5 carboxyl groups also to be disordered as changing of the position of the carboxyl hydrogen from $\mathrm{O} 4$ to $\mathrm{O} 5$ atom implies the change of bond orders (C19-O4 becomes a double bond, and C19-O5 a single). This is in accordance with the measured bond lengths of $1.269 \AA$ (C19-O4) and $1.267 \AA$ (C19-O5), which is intermediate between a carboxyl $\mathrm{C}-\mathrm{O}$ single $(1.21 \AA)$ and $\mathrm{C}=\mathrm{O}$ double bond $(1.31 \AA)$. This is due to the fact that the measured bond lengths are an average throughout the structure.

\section{CONCLUSION}

Although the Schiff base $\mathbf{1}$ and the dimethylformamide/water solvate 3 can be prepared both by LAG and in solution, in the case of pyridine solvates, the mechanochemical and conventional synthesis have shown to be complementary; 2a was obtained only by LAG, whereas $\mathbf{2 b}$ formed quantitatively from solution. A possible reason for this is larger water/pyridine ratio in the LAG experiment (as water is produced by the condensation reaction). The presence of two carboxyl groups on the Schiff base molecule leads to a specific hydrogen bonding pattern in the crystal structure. The high stability of this hydrogen bonding pattern was evidenced not only by a high melting/decomposition temperature of $\mathbf{1}$, but also by the fact that upon the loss of solvent molecules all the solvates transform into $\mathbf{1}$. The specific hydrogen bonding patterns in $\mathbf{1}$ and its solvates have some effect on the keto-enol equilibrium in the solid state, as a hydrogen bond to the carbonyl oxygen apparently stabilises the keto-amine tautomer.

Acknowledgements. This research was supported by grants from the Ministry of Science and Technology of the Republic of Croatia (Grant No. 119-1193079-3069). 


\section{REFERENCES}

1. L. F. Fieser and M. Fieser, Advanced Organic Chemistry, Reinhold Publishing Corporation, New York, 1961.

2. F. H. Allen, Acta Crystallogr. B58 (2002) 380-388.

3. A. Blagus, D. Cinčić, T. Friščić, B. Kaitner, and V. Stilinović, Mac. J. Chem. Chem. Eng. 29 (2010) 117-138.

4. R. H. Holm, G. W. Everett, and A. Chakravorty, Progr. Inorg. Chem. 7 (1966) 83-214.

5. R. Kitaura, G. Onoyama, H. Sakamoto, R. Matsuda, S.-I. Noro, and S. Kitagawa, Angew. Chem. Int. Ed. 43 (2004) 2684-2687.

6. K. C. Gupta and A. K. Sutar, Coord. Chem. Rev. 252 (2008) 1420-1450.

7. P. G. Lacroix, Eur. J. Inorg. Chem. 2001 339-348.

8. G. Rajsekhar, C. P. Rao, P. Saarenketo, K. Nattinen, and K. Rissanen, New J. Chem. 28 (2004) 75-84.

9. J. Lewiński, J. Zachara, I. Justyniak, and M. Dranka, Coord. Chem. Rev. 249 (2005) 1185-1199.

10. S. Di Bella, I. Fragala, I. Ledoux, M. A. Diaz-Garcia, and T. J. Marks, J. Am. Chem. Soc. 119 (1997) 9550-9557.

11. A. K. Sah, T. Tanase, and M. Mikuriya, Inorg. Chem. 45 (2006) 2083-2092.

12. D. Cinčić and B. Kaitner, CrystEngComm 13 (2011) 4351-4357.

13. V. Stilinović and T. Portada, Acta Crystallogr. E67 (2011) o3013.

14. K. Užarević, I. Đilović, D. Matković-Čalogović, D. Šišak, and M. Cindrić, Angew. Chem. Int. Ed. 47 (2008) 7022-7025.

15. P. A. Vigato and S. Tamburini, Coord. Chem. Rev. 248 (2004) 1717-2128.

16. P. D. Beer and P. A. Gale, Angew. Chem. Int. Ed. 40 (2001) 486516.

17. H. K. Shapiro, Am. J. Ther. 5 (1998) 323-353.

18. H. Chen and J. Rhodes, J. Mol. Med. 74 (1996) 497-504.

19. O. P. Anderson, A. la Cour, M. Findeisen, L. Hennig, O. Simonsen, L. F. Taylor, and H. Toftlund, J. Chem. Soc. Dalton Trans. 1997 111-120.

20. S. Uhlenbrock, R. Wegner, and B. Krebs, J. Chem. Soc. Dalton Trans. 1996 3731-3736.

21. H. Dürr, Angew. Chem. Int. Ed. 28 (1989) 413-431.

22. E. Hadjoudis and I. M. Mavridis, Chem. Soc. Rev. 33 (2004) 579-588.

23. B. Kaitner and M. Zbačnik, Acta Chim. Slov. 59 (2012) 670-679.

24. M. Gavranić, B. Kaitner, and E. Meštrović, J. Chem. Cryst. 26 (1996) 23-28.

25. H. Pizzala, M. Carles, W. E. E. Stone, and A. Thevand, J. Chem. Soc. Perkin Trans. 2 (2000) 935-939.

26. H. Nazır, M. Yıldız, H. Yılmaz, M. N. Tahir, and D. Ülkü, J. Mol. Struct. 524 (2000) 241-250.

27. K. Wozniak, H. He, J. Klinowski, W. Jones, T. Dziembowska, and E. Grech, J. Chem. Soc. Faraday Trans. 91 (1995) 77-85.

28. K. Užarević, M. Rubčić, V. Stilinović, B. Kaitner, and M. Cindrić, J. Mol. Struct. 984 (2010) 232-239.

29. A. Elmali, M. Kabak, E. Kavlakoglu, Y. Elerman, and T. N. Durlu, J. Mol. Struct. 510 (1999) 207-214.

30. A. D. Khalaji, K. Fejfarova, and M. Dusek, Acta Chim. Slov. 57 (2010) 257-261.

31. M. Yıldız, H. Özay, H. Ünver, N. O. İskeleli, D. M. Zengin, and T. N. Durlu, J. Chem. Crystallogr. 40 (2010) 909-913.

32. A. D. Khalaji, K. Fejfarova, M. Dusek, and H. R. Bijanzadeh, J. Chem. Crystallogr. 41 (2011) 1955-1960.

33. V. Stilinović, D. Cinčić, and B. Kaitner, Acta Chim. Slov. 55 (2008) 874-879.
34. J. Schmeyers, F. Toda, J. Boyb, and G. Kaupp, J. Chem. Soc. Perkin Trans. 2 (1998) 989-993.

35. G. Rothenberg, A. P. Downie, C. L. Raston, and J. L. Scott, J. Am. Chem. Soc. 123 (2001) 8701-8708.

36. G. Kaupp and J. Schmeyers, Angew. Chem. Int. Ed. 32 (1993) 1587-1589.

37. O. Dolotko, J. W. Wiench, K. W. Dennis, V. K. Pecharsky, and V. P. Balema, New J. Chem. 34 (2010) 25-28.

38. G. Kaupp, J. Schmeyers, and J. Boy, Tetrahedron 56 (2000) 6899-6911.

39. G. Kaupp, Topics Curr. Chem. 254 (2005) 95-183.

40. T. Friščić, A. V. Trask, W. Jones, and W. D. S. Motherwell, Angew. Chem. Int. Ed. 45 (2006) 7546-7550.

41. N. Shan, F. Toda, and W. Jones, Chem. Commun. (2002) 2372-2373.

42. T. Friščić, D. G. Reid, I. Halasz, R. S. Stein, R. E. Dinnebier, and M. J. Duer, Angew. Chem., Int. Ed. 49 (2010) 712-715.

43. V. Štrukil, L. Fabian, D. G. Reid, M. J. Duer, G. J. Jackson, M. Eckert-Maksić, and T. Friščić, Chem. Commun. 46 (2010) 9191-9193.

44. S. L. James, C. J. Adams, C. Bolm, D. Braga, P. Collier, T. Friščić, F. Grepioni, K. D. M. Harris, G. Hyett, W. Jones, A. Krebs, J. Mack, L. Maini, A. G. Orpen, I. P. Parkin, W. C. Shearouse, J. W. Steed, and D. C. Waddell, Chem. Soc. Rev. 41 (2012) 413-447.

45. D. Braga, S. L. Giaffreda, F. Grepioni, A. Pettersen, L. Maini, M. Curzi, and M. Polito, Dalton Trans. 2006 1249-1263.

46. D. Cinčić, M. Juribašić, D. Babić, K. Molčanov, P. Šket, J. Plavec, and M. Curić, Chem. Commun. 47 (2011) 11543-11545.

47. M. Cindrić, M. Uzelac, D. Cinčić, I. Halasz, G. Pavlović, T. Hrenar, M. Curić and D. Kovačević, CrystEngComm 14 (2012) 3039-3045.

48. D. Cinčić, I. Brekalo, and B. Kaitner, Cryst. Growth Des. 12 (2012) 44-48.

49. STARe Software V.9.01., Mettler-Toledo GmbH, 2006

50. OPUS 4.0, Brucker Optik GmbH, 2003.

51. Oxford Diffraction (2003), CrysAlis CCD and CrysAlis RED. Version 1.170., Oxford Diffraction Ltd, Wroclaw, Poland.

52. G. M. Sheldrick, Acta Crystallogr. A64 (2008) 112-122.

53. L. J. Farrugia, WinGX, J. Appl. Cryst. 32 (1999) 837-838.

54. Crystallographic data have been deposited with the Cambridge Crystallographic Data Centre, 12 Union Road, Cambridge, CB2 1EZ, UK (fax: +44 1223 336033; e-mail: deposit@ccdc.ac.uk or www: http://www.ccdc.cam.ac.uk). These data can be obtained free of charge from the Director upon request quoting the CCDC deposition numbers 887385-887387.

55. L. J. Farrugia, ORTEP-3 for Windows, J. Appl. Crystallogr. 30 (1997) 565.

56. C. F. Macrae, I. J. Bruno, J. A. Chisholm, P. R. Edgington, P. McCabe, E. Pidcock, L. Rodriguez-Monge, R. Taylor, J. v. d. Streek, and P. A. Wood, J. Appl. Crystallogr. 41 (2008) 466-470.

57. Philips X'Pert Data Collector 1.3e, Philips Analytical B. V. Netherlands, 2001.

58. Philips X'Pert Graphic \& Identify 1.3e Philips Analytical B. V. Netherlands, 2001

59. Philips X'Pert Plus 1.0, Philips Analytical B. V. Netherlands, 1999.

60. B. R. Bhogala, P. Vishweshwar, and A. Nangia, Cryst. Growth Des. 2 (2002) 325-328.

61. V. Stilinović and B. Kaitner, Cryst. Growth Des. 12 (2012) 5763-5772.

62. V. Stilinović and B. Kaitner, Cryst. Growth Des. 11 (2011) 4110-4119. 